\title{
A large-scale neurocomputational model of emotional decision
} making

\author{
Abninder Litt*1, Chris Eliasmith ${ }^{2,3}$ and Paul Thagard ${ }^{1,2,4}$
}

\author{
Address: ${ }^{1}$ David R. Cheriton School of Computer Science, University of Waterloo, Ontario, Canada, ${ }^{2}$ Department of Philosophy, University of \\ Waterloo, Ontario, Canada, ${ }^{3}$ Department of Systems Design Engineering, University of Waterloo, Ontario, Canada and ${ }^{4}$ Department of \\ Psychology, University of Waterloo, Waterloo, Ontario, Canada \\ Email: Abninder Litt* - alitt@uwaterloo.ca \\ * Corresponding author
}

from Sixteenth Annual Computational Neuroscience Meeting: CNS*2007

Toronto, Canada. 7-12 July 2007

Published: 6 July 2007

BMC Neuroscience 2007, 8(Suppl 2):PI4 doi:I0.I I86/I47I-2202-8-S2-PI4

〔 2007 Litt et al; licensee BioMed Central Ltd.

There is growing interest in exploring the neurological activity underlying valuation and decision making. Recent findings have greatly enriched behavioral investigations of the psychology of preference and choice by revealing the specific biological substrates of reward encoding, trust, risky choice, and other relevant phenomena. Neurocomputational modeling allows for precise integrations of empirical findings into detailed mechanisms for how specific brain operations can produce complex cognitions and behaviors. We present a biologically realistic spiking neural model of affective choice and judgment that demonstrates this important explanatory role for computational neuroscience.

Our model proposes a fundamental interplay between an emotional arousal state encoded by the amygdala and judgments of reward value and valuation changes computed in orbitofrontal cortex. Inspired by findings from attention research, we model a multiplicative modulation of reward valuation by affective arousal, whereby highly emotive events or contexts cause an amplification of positive or negative subjective judgments. This modulated signal feeds into interacting opponent systems for computing positive and negative reward prediction errors, which we have respectively encoded through dopaminergic and serotonergic activity. The degree to which an obtained outcome was positively or negatively unexpected induces activity in our modeled anterior cingulate and dorsolateral prefrontal cortical areas regarding the behavioral relevance of the outcome, with negative surprises indicating current behavior may need to be modified. A consolidation of encoded valuation, saliency and relative surprise is proposed to drive the planning of stimulus-appropriate behavior. Finally, information regarding behavioral saliency and prediction error feeds back to modulate emotional arousal level itself. These modeled mechanisms help to explain several important findings of behavioral decision research.

In particular, the model provides a rigorous biological account of prospect theoretic loss aversion by encoding an asymmetric influence of the effects of positive and negative outcomes on emotional arousal, which produces disparities in subjective valuations of equivalent losses and gains. Mechanisms for relative valuations and neural firing saturation effects in orbitofrontal cortex further contribute to an explanation of the shape of the observed value function from prospect theory. The model also suggests multiple distinct neurological mechanisms by which information framing may affect choices, including ones involving anticipated pleasure. This allows for the proposal of a detailed neural basis for observed interactions between affect, prior expectations and counterfactual comparisons considered at the behavioral level in decision affect theory. Simulations of these important emotional decision phenomena lend support to the specific mechanisms of cognitive-affective interaction implemented in our model, and show the valuable role compu- 
tational neuroscience can play in developing richer and more complete explanations in cognitive psychology.

Publish with Bio Med Central and every scientist can read your work free of charge

"BioMed Central will be the most significant development for disseminating the results of biomedical research in our lifetime. " Sir Paul Nurse, Cancer Research UK

Your research papers will be:

- available free of charge to the entire biomedical community

- peer reviewed and published immediately upon acceptance

- cited in PubMed and archived on PubMed Central

- yours - you keep the copyright

Submit your manuscript here:

http://www.biomedcentral.com/info/publishing_adv.asp 